\title{
EDUCAÇÃO FÍSICA ESCOLAR A
}

\section{CAMINHO DA INCLUSÃO: A}

INSERÇÃO DOS ALUNOS COM

NECESSIDADES EDUCATIVAS

\section{ESPECIAIS}

Prof. Dr. Gabriel César Dias Lopes, PhD

\section{Resumo}

Esta pesquisa discute de que forma as escolas brasileiras estão preparadas para receber os alunos com necessidades especiais, evidenciando a educação física escolar, nas classes regulares e a forma como essa deve ser tratada e dirigida aos alunos com necessidades educacionais especiais. Enfoca também a formação para o cuidado especial que os profissionais da área de educação e saúde precisam ter com essa parcela população, carente de atenção familiar e psicossocial. Para tanto, a metodologia utilizada é uma revisão teórica bibliográfica, onde as experiências recolhidas por vários profissionais demonstram que é possível realizar o trabalho inclusivo, baseado além de um conhecimento técnico pedagógico, também na aproximação do professor de educação física com o universo de um aluno com NEE.

Palavras-Chave: Necessidades Educacionais Especiais, Educação Física Escolar, Inclusão.

\section{Abstract}

This research argues of that it forms the Brazilian schools are prepared to receive the pupils with necessities special, evidencing the pertaining to school physical education, in the regular 
classrooms and the form as this must be treated and be directed to the pupils with educational necessities special. It also focuses the formation for the special care that the professionals of the education area and health need to have with this parcel population, devoid of familiar and psicossocial attention. For in such a way, the used methodology is a bibliographical theoretical revision, where the experiences collected for some professionals demonstrate that it is possible to carry through the inclusive work, established beyond a knowledge pedagogical technician, also in the approach of the professor of physical education with the universe of a pupil with NEE.

\section{Word-Keys: Educational necessities Special, Pertaining to school Physical Education, Inclusion.}

\section{Resumen}

Esta investigación discute cómo las escuelas brasileñas están preparadas para recibir estudiantes con necesidades especiales, destacando la educación física escolar, en clases regulares y cómo debe ser tratada y dirigida a los estudiantes con necesidades educativas especiales. También se enfoca en la capacitación para la atención especial que los profesionales en el área de educación y salud necesitan tener con esta porción de la población, sin atención familiar y psicosocial. Para ello, la metodología utilizada es una revisión bibliográfica teórica, donde las experiencias recogidas por varios profesionales demuestran que es posible realizar un trabajo inclusivo, basado además de un conocimiento técnico pedagógico, también en la aproximación del profesor de educación física al universo de un alumno con NEE.

Palabras clave: Necesidades educativas especiales, educación física escolar, inclusión.

* Gabriel César Dias Lopes é Ph.D é Graduado em: Teologia, Direito, Administração e Recursos Humanos, MBA em Marketing e Gestão Estratégica, Pós-Graduado em Psicanálise, Coordenador do Curso de Pós Graduação Lato Sensu em Psicanálise Clinica da FABIC, Pós Graduado em Acupuntura, Pós Graduado em Homeopatia, Mestre em Educação, Mestre em Administração, Doutor em Educação e um Ph.D em Psicanálise. Membro da International Special Court of Arbitration and Human Rights - Registro: ISCAHRGCDL-17/11n2016, Membro 
da Comissão Científica da Olympus Intellectual Center, Atenas (Grecia), Presidente da LUI - Logos University International. Premiado com a Medalha Manoel Tubino - 90 Anos da Federação Internacional de Educação Física.

\section{INTRODUÇÃO}

O termo inclusão talvez seja na contemporaneidade a maior demanda e a maior temática nos meios pedagógicos. Sua abrangência, porém, ultrapassa as discussões de acessibilidade comuns no dia a dia e perpassa o âmbito da lei. passa do simples acesso a um banheiro público até os mais sofisticados computadores que são devidamente adaptados para incluir os cidadãos que normalmente deveria ser incluído.

Nesse sentido, é notório que no Brasil, poucas escolas estão realmente preparadas para assumir crianças com necessidades especiais e o que não falta são relatos de mães que comprovam isto e que será visto no anexo deste trabalho. Aqui, se vai caminhar sobre um país tão grande e que de acordo com o site do Instituto Nacional de Estudos e Pesquisas Educacionais Anísio Teixeira - INEP atende hoje na escola pública cerca de 45 milhões de alunos.

Acerca disso, não é difícil imaginar que visivelmente não é feito muita coisa para inclusão de pessoas com necessidades especiais nas escolas de forma geral, mas, especificamente no tema que mais sustenta esta pesquisa que é a inclusão de estudantes com NEE nas aulas de educação física nas escolas públicas brasileiras pouca coisa também está sendo feita.

Em termos numéricos, três em cada quatro escolas do país não contam com itens básicos de acessibilidade, como rampas, corrimãos e sinalização. Menos de um terço possui sanitários adaptados para deficientes. É o que revela o Censo Escolar 2014, do Instituto Nacional de Estudos e Pesquisas Educacionais Anísio Teixeira (Inep). De acordo com dados tabulados pela Fundação Lemann e pela Meritt, responsáveis pelo portal QEdu, indicam que apenas 23 municípios do Brasil contam com todas as suas escolas acessíveis - incluindo banheiros totalmente adequados a deficientes.

Ou seja, a porcentagem das escolas não está devidamente adequada para portadores de 
necessidades especiais, e com isso, a exclusão é notória. Paralelo a isso, segundo dados do Instituto Brasileiro de Geografia e Estatística (IBGE) Em 2014, mais de 698 mil estudantes especiais estavam matriculados em classes comuns. Percentual sobe para $93 \%$ em escolas públicas.

Uma das questões que precisam ficar claras na execução deste trabalho é a compreensão do que realmente legitima a palavra inclusão, que por diversas vezes pode ser confundida com integrar ou simplesmente inserir em uma determinada turma ou grupo de pessoas. A inserção ou inclusão perpassa por esferas digitais, sociais e físicas e pode igualmente fragmentar estes nomes em diversos campos.

Nesse sentido, a inclusão em seus diversos aspectos tem o poder de restaurar uma vida sem sombra de dúvidas. Na educação ou no âmbito escolar existem a possibilidade de ser a escola o lugar ideal para destruir a estima de pessoa excluindo-a ou o local com o poder da inserção de uma pessoa em um determinado meio pode salvá-la.

No Brasil, é visível que grande parte das escolas não comporta meios físicos para incluir deficientes. Está também evidente que dentro das exceções a prioridade são as rampas de acesso, como se este fosse o único meio ou a única opção que dá respaldo a questão da inclusão para portadores de NEE nas escolas, entretanto, parece um sentimento legitimo diante da dificuldade que é para consegui-las.

Mesmo amparado pela lei constitucional de 1988 como cidadãos que tem os mesmos direitos de todos, os pais sofrem com rejeições por parte de diretoras, não por discriminação, mas por falta de estrutura física e profissional das instituições de ensino. No Art. 208, está previsto que o dever do Estado com a educação será efetivado mediante a garantia de: II atendimento educacional especializado aos portadores de deficiência, preferencialmente na rede regular de ensino.

Nesse sentido, este artigo é mais um no rol de pesquisas relacionadas à inclusão social, especificamente no âmbito educacional, e que mostra que a "deficiência" parte das escolas por não ter estrutura física adequada para receber um aluno com uma necessidade especial, principalmente em instituições do interior. Não obstante se tratar de percorrer os benefícios que este estudante desfruta em sua vida em todos os aspectos.

Há evidências que muito sobre este tema está disponível para consulta quando se trata de uma teórica incompetência do Estado nesse aspecto, seja ela proposital ou não. Existe um direito legal para estas crianças e adolescentes e em uma visão geral, o amparo da lei e discussões está aberto para a inclusão como a Lei 7.853 de 1989, o Estatuto da Criança e 
Adolescente - ECA, Declaração de Salamanca, Lei de Diretrizes e Bases - LDB, Lei 10.172 referente ao Plano Nacional de Educação (PNE), entre outras discussões a respeito do tema.

Sendo assim, o que fica claro é que existem muitas teorias e, muitas discussões, o problema é visível, é conhecido, é lógico, o que teoricamente está ausente são as ações que concretizam a sensibilidade proposta por especialistas e por leis, e fica o alerta para que as ideias saiam do papel.

Esta pesquisa será bibliográfica, de cunho qualitativo e dedutivo analisando informações previas sobre o tema, buscando também em legislação básica dados que possam direcionar a pesquisa. O trabalho está dividido em uma introdução e mais cinco subtópicos. No primeiro é traçado o conceito de educação física escolar e sua aplicação seguindo os parâmetros da LDBEN e PCNS. No segundo é discutido o conceito de inclusão social em suas possibilidades de aplicação e entraves encontrados na implementação. No terceiro é traçada a previsão legal da inclusão e das aulas de educação física dentro desse contexto. No quinto é trazido o papel da escola no contexto e no processo de inclusão, e no sexto e último capítulo é enfatizado os limites e as possibilidades do fazer pedagógico dentro do contexto e visão de educação inclusiva.

As considerações finais trazem um pouco do entendimento obtido com este estudo e vislumbram as possibilidades de uma educação física escolar diferenciada para os alunos com necessidades educacionais especiais.

\section{A EDUCAÇÃO FÍSICA ESCOLAR}

O mito da normalidade parte do paradigma do homem padrão fabricado por uma geração de pessoas que tinha dificuldade de compreender as pessoas que nasciam, ou se tornavam, diferentes _ deficiências físicas, intelectuais, sociais. É uma construção cultural que esteve enraizada e estagnada na mesmice durante a era moderna, mas ganhou novas acepções na era pós-moderna.

No que se refere à escola, se deve ter em mente que ela foi estruturada a partir de um tipo de racionalidade moderna, respondendo a um projeto de Modernização. O nascimento da escola recebe sustentação desse contexto de repetição, linearidade, modelo, Estado como estruturador da organização social - instituições como família, escola, Igreja.Vale destacar que a escola era vista como lugar onde os indivíduos dirigiam-se visando à aquisição de informações, ou seja, a conquista do conhecimento. O SABER instituído pela escola era 
promotor de inserção do indivíduo à sociedade como um todo.

O projeto de escola provém de uma formatação de conhecimentos legitimados que não abre espaço para a diversidade cultural proclamada pela nova era. Compreender as realidades culturais de diferentes grupos implica em organizar currículos flexíveis, construídos de forma a valorizar as diferentes manifestações culturais e reconhecer a possibilidade de articulação de seus atores/autores no cenário escolar.

A escola verdadeiramente democrática deve acolher em seu seio, sem gerar exclusão ou discriminação por insucesso escolar, a enorme diversidade de alunos com seus ritmos e modalidades diferenciados de aprendizagem. Traduz-se em ter professores que reconheçam as formas como seus alunos tratam e desenvolvem seus conhecimentos; atrelar metodologias diferenciadas de alunos capazes de acolher as diferenças existentes no espaço escolar e capacitar os alunos; tratar a avaliação como suporte para o acompanhamento do processo ensino aprendizagem e verificador das barreiras encontradas.

Porém, a escola apresenta como realidade, uma avaliação classificatória que hierarquiza os alunos - nem em suas possibilidades -, mas através de conhecimento adquirido. Uma formatação metodológica de ensino que trata os alunos como uma massa homogênea, onde aquele que não consegue apresentar bom desempenho não encontra apoio no espaço escolar. Sem falar na postura de grande parte do corpo docente, que de forma inflexível e desestimulada, não consegue uma relação com seus alunos que promova a aprendizagem deles.

À estruturação da organização social, por parte do Estado, ocorre por meio das políticas públicas que, dentre tantos direitos, precisava (e, ainda precisa) garantir os direitos sociais. Os direitos sociais que tinham como função assegurar que as desigualdades sociais não se ampliassem e assim comprometessem o exercício pleno dos direitos civis e políticos dos cidadãos (RUA, 1995).

Ações estrategicamente selecionadas a fim de consolidar a política pública que elimine a exclusão. Neste sentido, a política pública necessita ter um caráter imperativo para que sua autoridade realmente alcance o fim desejado e contemple todos os cidadãos. Porém, no caso das chamadas minorias, ou grupos vulneráveis, torna-se complexo implementar de forma imperativa uma política que confronte com a cultura do grupo social.

Em análise a esse aspecto do confronto, podemos observar as inúmeras tentativas do poder público de tentar implementar ações que garantam os direitos das pessoas com deficiência. A inclusão da pessoa com deficiência nos mais variados aspectos acaba por ser uma demanda recorrente, uma vez que há sempre a tentativa de reafirmar os seus direitos; e, uma 
vez mal resolvidos emergem continuamente no debate político e na agenda governamental.

Pelas recorrentes necessidades de pontuar a inclusão, quer seja por fatores culturais, quer seja pela falta de habilidade governamental, não se consegue controlar o seu processo. $\mathrm{O}$ processo de implementação de políticas públicas inclusivas necessita de cooperação entre as organizações participantes _ ou seja, todos da sociedade; necessita de uma programação que disponha de tempo e recursos suficientes; e, o fundamento da relação entre a causa e o efeito deve ser investigado sem superficialidade: a identidade.

A constituição da identidade do indivíduo se estabelece, entre outros aspectos, pela percepção da diferença do sujeito em relação aos demais presentes na sociedade. Identidade é uma construção relacional, marcada pela posição que a diferença pontua como aceitável (ou não) para o grupo ao qual o indivíduo está inserido. A diferença é fator contributivo ao processo, porque se encontra impregnada por símbolos, representações das normas e valores sociais. A representação atua para classificar o mundo e as relações existentes nos mais variados contextos.

Os Parâmetros Curriculares Nacionais - PCN's (BRASIL, 1997) quando se refere à educação física como a área do conhecimento que introduz e integra os alunos na cultura corporal do movimento, com as finalidades de lazer, expressão de sentimentos, afetos e emoção, manutenção e melhoria da saúde. Aponta para a perspectiva metodológica de ensino e aprendizagem que busca o desenvolvimento da autonomia, cooperação, participação social e da afirmação de valores e princípios e valores democráticos.

Estes princípios democráticos visam à recuperação de qualquer tipo de discriminação e exclusão social. Ainda segundo os (PCNs), sobre o papel da escola e do professor de educação física, dizem que a escola configura-se como um espaço diferenciado aonde as diferentes competências com os quais as crianças chegam à escola deverão ser ressignificadas e ao professor é atribuída a função de oportunizar uma variedade de atividades em que diferentes competências sejam exercidas e as diferenças individuais sejam valorizada.

\section{INCLUSÃO SOCIAL: CONCEITOS E PARADIGMAS.}

O paradigma da inclusão é uma das maiores demandas da contemporaneidade. Fala-se muito atualmente dessa demanda pela inclusão e principalmente na questão das pessoas com 
deficiência esse fator é ainda mais significativo quando se refere ao ensino da matemática nas escolas e toma uma dimensão ainda mais especial quando se refere aos alunos especiais.

É comum ouvir relatos dos professores, a respeito dos trabalhos que desenvolveram com alunos em suas respectivas salas de aula, sobre o conteúdo, os recursos didáticos utilizados, a forma como estes eram organizados e, até mesmo, a ordem em que eram dispostos. Todos os debates ainda que se mostrem repleto de aprendizagens mostra também a linha tênue entre as possibilidades e os entraves práticos da inclusão em sala de aula.

Entende-se por inclusão um conjunto de formas e ações que combatem a exclusão ao acesso básico das benesses da vida em sociedade, motivadas pelo fato de não haver pertencimento à classe social, origem geográfica, educação, idade, padrões de uma determinada sociedade ou ainda pela existência de deficiência ou preconceitos raciais.

Assim, Inclusão Social seria oferecer aos exclusos dessas categorias, oportunidades de acesso a bens e serviços, dentro de um sistema que beneficie a todos e não apenas aos mais favorecidos no sistema piramidal em que vivemos.

Segundo (ARANHA, 2001, apud ALVES 2005 p. 61)

O conceito de inclusão [...] evocaria a necessidade de transformação da escola para permitir o atendimento integrado de todos os alunos no ensino comum. Nesse caso, são defendidas as medidas de profundas alterações na organização do ensino, colocando em discussão a necessidade de análise coletivas sobre o projeto pedagógico da instituição; questionando as alternativas didáticas consideradas 'tradicionais' e centradas no professor; propondo a revisão de processos de avaliação (avaliação processual que considere o aluno como parâmetro de si mesmo); construindo dispositivos de apoio complementar ao atendimento no ensino comum, sem excluir o aluno de sua classe de referência; discutindo amplamente a necessidade de formação continuada de professores e demais técnicos que atuam junto às escolas." (ARANHA, 2001, apud ALVES 2005 p. 61)

O discurso da inclusão foi ganhando força com a democratização da sociedade e em especial no Brasil, a partir da última década do século XX, quando as modificações políticas e sociais vivenciadas pelo país, evocou o surgimento de grupos que até então por serem minorias sociais, viviam à margem da sociedade. Uma lista de excluídos como povos, indígenas, idosos, deficientes físicos e mentais, homossexuais, encabeçam essa lista, fora outros tantos excluídos que na verdade constituem grande maioria da população como mulheres, negros, sem-terra, sem-teto, etc.Como este trabalho se restringe ao grupo excluído dos deficientes intelectuais, vamos ater a esses as considerações. De acordo com Steinbeck, 1999, pag:30

A elaboração de políticas e leis na criação de programas e serviços voltados ao atendimento das necessidades especiais de deficientes consiste em criar mecanismos que adaptem os deficientes aos sistemas sociais comuns e, em caso de incapacidade por parte de alguns deles, criar-lhes sistemas especiais em que possa, participar ou "tentar" acompanhar a ritmo dos que não tenham alguma deficiência específica. Tem 
sido prática comum deliberar e discutir acerca da inclusão de pessoas com algum tipo de deficiência: mencionando direitos inerentes a uma deficiência específica, abrangendo todos os direitos de forma generalizada, embrulhando-os, sem maiores cuidados em mostrar detalhadamente estes.

A fala da autora mostra que por ser um conceito novo e de certa forma em moda no entorno social , falar de inclusão, ou melhor, inseri-la requer cuidados que a própria sociedade não está pronta para assumir, a própria educação para a inclusão precisa de um trabalho de educação desde sua raiz, é nos primórdios da vida social, na cultura local que deve ser implementado o conceito de inclusão para que ele funcione e não apenas através de imposições sociais ou governamentais que não mudam o padrão mental e de comportamento das pessoas. O comportamento de excluir, restringir, subjgar, julgar é muito enraizado socialmente.

Para Mantoan (1991, pag: 25) :

A inclusão é uma inovação, cujo sentido tem sido muito distorcido e um movimento muito polemizado pelos mais diferentes segmentos educacionais e sociais. No entanto, inserir alunos com déficits de toda ordem, permanentes ou temporários, mais graves ou menos severos no ensino regular nada mais é do que garantir o direito de todos à educação - e assim diz a Constituição!.

Dessa forma, o princípio democrático da educação para todos só se evidencia nos sistemas educacionais que se especializam em todos os alunos, não apenas em alguns deles, os alunos com deficiência. A inclusão, como consequência de um ensino de qualidade para todos os alunos provoca e exige da escola brasileira novos posicionamentos. Pesquisadores como Tabaquim (1996), Paiva (1997), Nascimento (1998), Limongi (2003),Alpino (2003) e Carabetti (2005) comprovaram a importância de estudar os processos de ensino-aprendizagem e as relações sociais de crianças com necessidades educacionais especiais na escola, e em particular atenção aos estudantes com paralisia cerebral.

Na teoria de Vygotsky (1998) existem dois níveis de desenvolvimento:um real, já adquirido ou formado, que determina o que o estudante já é capaz de fazer por si próprio, e um potencial, ou seja, a capacidade de aprender com outra pessoa. Os níveis de desenvolvimento formam a Zona de Desenvolvimento Proximal.

Essa zona pode ser entendida como a distância entre o nível de desenvolvimento real e o potencial. Sendo que o nível real se refere ao conhecimento já conquistado pela criança e o potencial como aquele que ela necessita de ajuda de adultos ou de companheiros mais experientes. Para Vygotsky, o trabalho do sujeito refere-se ao domínio dos instrumentos de mediação, inclusive sua transformação por uma atividade mental.

Tomando como referência a teoria de Vygotsky entende-se que a aprendizagem interage 
com o desenvolvimento, criando abertura nas zonas de desenvolvimento proximal, nas quais, as interações são realizadas, estando então, os dois processos, aprendizagem e desenvolvimento, inter-relacionados. Desta forma, um conceito que se pretende trabalhar, requer sempre um grau de experiência anterior para a criança.

Nos dias atuais tem-se aumentado o debate da educação inclusiva, de um modo geral. As políticas públicas têm se preocupado mais com essa questão, ao ser abordado alunos com diversos tipos de deficiências. Em se tratando da paralisia cerebral, percebe-se a falta de debates e discussões sobre o problema, uma vez que os alunos desse grupo apresentam formas e tempos diferentes de aprendizagem. Existe uma barreira formada entre os velhos padrões e práticas escolares e padrões mais recentes. Esse tipo de problema acontece quando a escola recebe esse tipo de aluno e todas as suas práticas são postas em questão e novas temáticas devem ser elaboradas e colocadas em prática.

Percebe-se então que a escola não está preparada para todos os alunos. A escola só está pronta para alunos que podem superar as dificuldades que venham a surgir, por seu próprio esforço, com a sua habilidade cognitiva. Aqueles que dependem se um maior apoio por parte do professor e da própria logística da escola, fica à mercê da sorte.

\section{ARGUMENTAÇÃO LEGAL}

A Constituição Federal de 1988 traz como um dos seus objetivos fundamentais "promover o bem de todos, sem preconceitos de origem, raça, sexo, cor, idade e quaisquer outras formas de discriminação" (art.3º inciso IV). Define, no artigo 205, a educação como um direito de todos, garantindo o pleno desenvolvimento da pessoa, o exercício da cidadania e a qualificação para o trabalho.

No seu artigo 206, inciso I, estabelece a "igualdade de condições de acesso e permanência na escola" como um dos princípios para o ensino e garante, como dever do Estado, a oferta do atendimento educacional especializado, preferencialmente na rede regular de ensino (art. 208).

O Estatuto da Criança e do Adolescente - ECA, Lei n ${ }^{\circ}$ 8.069/90, no artigo 55, reforça os dispositivos legais supracitados ao determinar que "os pais ou responsáveis têm a obrigação de matricular seus filhos ou pupilos na rede regular de ensino". Também nessa década, documentos como a Declaração Mundial de Educação para Todos (1990) e a Declaração de 
Salamanca (1994) passam a influenciar a formulação das políticas públicas da educação inclusiva.

Em 1994, é publicada a Política Nacional de Educação Especial, orientando o processo de "integração instrucional" que condiciona o acesso às classes comuns do ensino regular àqueles que “(...) possuem condições de acompanhar e desenvolver as atividades curriculares programadas do ensino comum, no mesmo ritmo que os alunos ditos normais" (p.19).

Ao reafirmar os pressupostos construídos a partir de padrões homogêneos de participação e aprendizagem, a Política não provoca uma reformulação das práticas educacionais de maneira que sejam valorizados os diferentes potenciais de aprendizagem no ensino comum, mas mantendo a responsabilidade da educação desses alunos exclusivamente no âmbito da educação especial.

A atual Lei de Diretrizes e Bases da Educação Nacional, Lei nº 9.394/96, no artigo 59, preconiza que os sistemas de ensino devem assegurar aos alunos currículo, métodos, recursos e organização específicos para atender às suas necessidades; assegura a terminalidade específica àqueles que não atingiram o nível exigido para a conclusão do ensino fundamental, em virtude de suas deficiências; e assegura a aceleração de estudos aos superdotados para conclusão do programa escolar.

Também define, dentre as normas para a organização da educação básica, a "possibilidade de avanço nos cursos e nas séries mediante verificação do aprendizado" (art. 24, inciso V) e "[...] oportunidades educacionais apropriadas, consideradas as características do alunado, seus interesses, condições de vida e de trabalho, mediante cursos e exames" . (LDB, 1996,art. 37 ).

Em 1999, o Decreto $n^{\circ} 3.298$, que regulamenta a Lei $n^{\circ} 7.853 / 89$, ao dispor sobre a Política Nacional para a Integração da Pessoa Portadora de Deficiência, define a educação especial como uma modalidade transversal a todos os níveis e modalidades de ensino, enfatizando a atuação complementar da educação especial ao ensino regular. Acompanhando o processo de mudança, as Diretrizes Nacionais para a Educação Especial na Educação Básica, Resolução CNE/CEB n ${ }^{\circ}$ 2/2001, no artigo $2^{\circ}$, determinam que:

Os sistemas de ensino devem matricular todos os alunos, cabendo às escolas organizarem-se para o atendimento aos educandos com necessidades educacionais especiais, assegurando as condições necessárias para uma educação de qualidade para todos. (MEC/SEESP, 2001).

As Diretrizes ampliam o caráter da educação especial para realizar o atendimento educacional especializado complementar ou suplementar à escolarização, porém, ao admitir a possibilidade de substituir o ensino regular, não potencializam a adoção de uma política de 
educação inclusiva na rede pública de ensino, prevista no seu artigo $2^{\circ}$.

O Plano Nacional de Educação - PNE, Lei no 10.172/2001, destaca que "o grande avanço que a década da educação deveria produzir seria a construção de uma escola inclusiva que garanta o atendimento à diversidade humana". Ao estabelecer objetivos e metas para que os sistemas de ensino favoreçam o atendimento às necessidades educacionais especiais dos alunos, aponta um déficit referente à oferta de matrículas para alunos com deficiência nas classes comuns do ensino regular, à formação docente, à acessibilidade física e ao atendimento educacional especializado.

A Convenção da Guatemala (1999), promulgada no Brasil pelo Decreto $n^{\circ}$ 3.956/2001, afirma que as pessoas com deficiência têm os mesmos direitos humanos e liberdades fundamentais que as demais pessoas, definindo como discriminação com base na deficiência toda diferenciação ou exclusão que possa impedir ou anular o exercício dos direitos humanos e de suas liberdades fundamentais.

Este Decreto tem importante repercussão na educação, exigindo uma reinterpretação da educação especial, compreendida no contexto da diferenciação, adotado para promover a eliminação das barreiras que impedem o acesso à escolarização.

\section{O PAPEL DA ESCOLA NO PROCESSO DE INCLUSÃO}

A escola assume um papel fundamental na vida da criança. Local de aprendizado, convivência, avanços, sendo assim ela não pode exercer função contrária levando essa criança a estacionar, retroceder, ou ser segregada em classes especiais e atendimentos à parte.O período que todo ser humano passa na escola é muito longo para que seja visto apenas como um laboratório onde as coisas ou as pessoas possam ser testadas à parte. É no conjunto que a escola se faz. Assim ela precisa garantir a aprendizagem e a equidade entre os alunos.

De acordo com (Mantóan, 2001 p: 33):

Um desses sistemas, que muito apropriadamente se denomina "de cascata", prevê a exclusão de algumas crianças, que têm déficits temporários ou permanentes e em função dos quais apresentam dificuldades para aprender. Esse sistema contrapõe-se à melhoria do ensino nas escolas, pois mantém ativo, o ensino especial, que atende aos alunos que caíram na cascata, por não conseguirem corresponder às exigências e expectativas da escola regular. Para se evitar a queda na cascata, na maioria das vezes sem volta, é preciso remar contra a correnteza, ou seja, enfrentar os desafios da 
inclusão: o ensino de baixa qualidade e o subsistema de ensino especial, desvinculada e justaposto ao regular.

Sendo assim a qualidade do ensino regular é, pois, um desafio que deve ser priorizado e assumido por todos os educadores. A escola regular para todas as crianças é um compromisso que toda nação deve assumir, pois do sucesso da educação básica depende o desenvolvimento econômico e social do país. S possibilidades para que isso se efetive são grandes, mas urge todo um remodelamento do sistema educacional que aí se encontra.

\begin{abstract}
Se hoje já podemos contar com uma Lei Educacional que propõe e viabiliza novas alternativas para melhoria do ensino nas escolas, estas ainda estão longe, na maioria dos casos, de se tornarem inclusivas, isto é, abertas a todos os alunos, indistinta e incondicionalmente. $\mathrm{O}$ que existe em geral são projetos de inclusão parcial, que não estão associados a mudanças de base nas escolas e que continuam a atender aos alunos com deficiência em espaços escolares semi ou totalmente segregados (classes especiais, salas de recurso, turmas de aceleração, escolas especiais, os serviços de intinerência). Infelizmente a presença de tudo isso não garante nem de leve a inclusão. (MANTÓAN, 2007, p:56)
\end{abstract}

A maioria das escolas não consegue atender os alunos com deficiência em suas turmas regulares e justificam esse fato a uma série de fatores entre os quais o despreparo dos professores para essa atuação. Além disso, há uma descrença bastante generalizada acerca da real aprendizagem e acompanhamento desses alunos especialmente os casos mais graves, que certamente acarretariam ainda uma maior exclusão desses alunos frente aos demais.

A inclusão é considerada pela escola mais uma utopia que uma possibilidade prática. Sendo assim, o que fica claro é a necessidade de se redefinir e de se colocar em ação novas alternativas e práticas pedagógicas, que favoreçam a todos os alunos, para isso há que se pautar na atualização e desenvolvimento de conceitos e em aplicações educacionais compatíveis com esse grande desafio.

A escola precisa urgentemente mudar para atender essa demanda. O que a lei propõe é um ensino especializado em todas as crianças e ainda mais especial para deficientes. Isso requer professores que se aperfeiçoam para exercer suas funções, atendendo às peculiaridades de todos os alunos, e mais especificamente os especiais. 


\section{OS DESAFIOS PARA A ESCOLA INCLUSIVA}

De acordo com Mantóan (2007, pag 78) alguns aspectos precisam ser seriamente considerados para que a escola seja realmente aberta a todos. É preciso mudar a escola e mais precisamente o ensino nela contido e isso não é tarefa fácil. É preciso colocar a aprendizagem e o ensino focado no aluno como eixo principal, garantindo que todos aprendam cada qual em seu respectivo tempo e criando situações para que a reprovação seja inexistente

Isso, dentro de nossa estrutura educacional seletiva e segregacionista é por si só muito difícil, e para tanto é preciso que a cooperação, o diálogo, a solidariedade, a criatividade e o espírito crítico sejam exercitados nas escolas, por professores, administradores, funcionários e alunos, pois são habilidades mínimas para o exercício da verdadeira cidadania.

Formar, valorizar e estimular o professor formando-o continuamente é outro aspecto que assume fundamental importância, visto que ele é instrumento fundamental para a aprendizagem do aluno. Para tanto sua valorização funcional é também aspecto relevante nisso tudo, principalmente para que professores dispostos e conscientes de sua função estejam exercitando seu trabalho.

O tema em uma visão geral é muito aberto, pois precisa de definições para que se entenda como funciona a educação física nas escolas e daí ter uma base de como ela pode e deve funcionar como pode ser usada com alunos especiais. É necessário entender a idade, os ciclos, as formas de jogos e a prática de esporte, entender como isto pode relacionar corpo e alma, [...] proporcionar aos alunos o desenvolvimento harmônico do corpo e do espírito, concorrendo assim para formar o homem de ação, física e moralmente sadio, alegre e resoluto, cônscio de seu valor e das suas responsabilidades ( BETTI, 2009b, p.82).

Conforme Frazão Souza (2016) a consistência da proposta de inclusão, basicamente, reside no processo de crítica e revisão de valores e crenças, no reconhecimento e respeito às diferenças, no exercício dialético de percepção da realidade que culmine no processo de luta pela participação de todos os que estejam em situação ou risco de exclusão. A garantia para todos da igualdade dos direitos sociais à participação e ao acesso de bens e serviços disponíveis no âmbito da sociedade, incluindo-se aí a Educação. No caso da escola, então que ela se configure democrática.

Em outra vertente, Vygotsky (1994) afirma que, desde o nascimento, os seres humanos são envolvidos em atividades e objetos que os permitem crescerem biologicamente, 
cognitivamente e socialmente; sendo que os objetos e as atividades não são aleatórias, as mesmas são permeadas pela cultura do grupo social a que pertencem esses seres.

\begin{abstract}
Desde os primeiros dias do desenvolvimento da criança, suas atividades adquirem um significado próprio num sistema de comportamento social e, sendo dirigidas a objetos definidos, são refratadas através do prisma do ambiente da criança. [...] Essa estrutura humana complexa é o produto de um processo de desenvolvimento enraizado nas ligações entre a história individual e a história social. (Vygotsky, 1994, p. 40).
\end{abstract}

Através da interação do outro, o ser humano que vai se constituindo sujeito pode, desde pequeno, ir atribuindo sentido ao que está em seu entorno. Dessa forma, esse sujeito vai desenvolvendo internamente as suas funções mentais superiores, atribuindo um significado intrapsíquico, a partir dos significados construídos nas relações sociais interpsíquicas.

São bases para essa interação, segundo Vygotsky (1994), os signos e os instrumentos. Sendo essa interação, a apropriação desses instrumentos a partir do contato entre os sujeitos. O contato é a mediação propriamente dita. O ser humano conseguiu evoluir como espécie graças à possibilidade de ter descoberto formas indiretas, mediadas, de significar o mundo ao seu redor, podendo, portanto, construir representações mentais de objetos, pessoas, situações, mesmo na ausência deles.

Essa mediação pode ser feita de duas formas: através do uso dos signos e do uso dos instrumentos. Ambos auxiliam no desenvolvimento dos processos psicológicos superiores. Os instrumentos e os signos proporcionariam, para Vygotsky (1994), a mediação que impulsionaria o desenvolvimento. Assim a interação com o outro e consequentemente a sua aprovação e aceitação que vão dar as bases do crescimento e desenvolvimento saudável dessa criança e do futuro adolescente. Quando o diálogo e a possibilidade de interação são danificados à construção mental emocional e mesmo de aprendizagem desse indivíduo fica seriamente comprometida.

\footnotetext{
O trabalho com esse público especial envolve um empenho e um esforço maior por necessitar também estimular a participação e envolvimento da família. Se a educação regular exige esse comprometimento, o ensino especial ainda mais, pois vai trabalhar com a desconstrução de situações condensadas na família e mexer com essas estruturas internas é sempre muito difícil, porém não impossível. . (AMARAL,1998, $\mathrm{p}: 04)$.
}

Para Amaral (1998, p:04) o aluno especial tem a marca da «especialidade» na escola e fora dos muros escolares. O aluno da classe especial é estigmatizado por ser considerado incapaz, por não pertencer ao grupo dos alunos ditos normais. Assim, considera que: ser especial na escola é deixar de pertencer à "espécie" dos normais, a dos que, pressupostamente, 
aprendem (...). Há um olhar patologizante e individualizado para aquele que não se encaixa, que não é normal.

Nesse sentido, é valido pensar os benefícios da educação física para pessoas com necessidades especiais. No prisma do governo, a teoria é perfeita, as discussões estão claras em diversos pontos de Leis e encontros, a preocupação está clara em documentos como a constituição, na Lei 7.853 de 24 de outubro de 1989:

O PRESIDENTE DA REPÚBLICA, faço saber que o Congresso Nacional decreta e eu sanciono a seguinte Lei :

Art. $1^{\circ}$ Ficam estabelecidas normas gerais que asseguram o pleno exercício dos direitos individuais e sociais das pessoas portadoras de deficiência, e sua efetiva integração social, nos termos desta Lei.

Percebe-se que o tema inclusão está distribuído em diversos documentos e, portanto, crianças e jovens com Necessidades Educacionais Especiais (NEE) deveriam ser contemplados com escolas que deveriam ter salas equipadas para o Atendimento Escolar Especial (AEE) que em diversos casos precisa auxiliares junto aos professores. No artigo 58 da LDB 9394/96, está claro o seguinte:

\begin{abstract}
Art. 58. Entende-se por educação especial, para os efeitos desta Lei, a modalidade de educação escolar, oferecida preferencialmente na rede regular de ensino, para educandos portadores de necessidades especiais. $\S 1^{\circ}$ Haverá, quando necessário, serviços de apoio especializado, na escola regular, para atender as peculiaridades da clientela de educação especial. $\S 2^{\circ} \mathrm{O}$ atendimento educacional será feito em classes, escolas ou serviços especializados, sempre que, em função das condições específicas dos alunos, não for possível a sua integração nas classes comuns do ensino regular. $\S 3^{\circ} \mathrm{A}$ oferta da educação especial, dever constitucional do Estado, tem início na faixa etária de zero a seis anos, durante a educação infantil.
\end{abstract}

E da mesma forma, o estudante com qualquer tipo de necessidade especial encontrará outros amparos legais conforme mostrados em anexos deste trabalho.

Rondinelli (2012) afirma sobre a educação física em geral:

\begin{abstract}
A Educação Física tem uma vantagem educacional que poucas disciplinas têm: o poder de adequação do conteúdo ao grupo social em que será trabalhada. Esse fato permite uma liberdade de trabalho, bem como uma liberdade de avaliação - do grupo e do indivíduo - por parte do professor, que pode ser bastante benéfica ao processo geral educacional do aluno"
\end{abstract}

Visto que é indiscutível os efeitos de inclusão para os alunos portadores de algum tipo de deficiência, entendendo que através dela o professor conhece melhor cada tipo de necessidade especial, deve-se atentar para as condições físicas das escolas brasileira que os 
professores sentem falta de material adequado para este de aula. (MAZZARINO, J.M; FALKENBACH, A.; RISSI, P. 87-102, 2011).

É sabido de todos que a maioria dos profissionais do Brasil passam por tais dificuldades e certamente ampliam seu campo de visão com o intuito de aprimorar as ações, mesmo com tantas dificuldades. Nesse sentido, existem questionamentos no momento de elaborar uma aula que possa colocar no mesmo ambiente um cadeirante e um aluno que não possua nenhum tipo de necessidade especial. (BRITO, LIMA. p. 1 - 12, 2012). Na questão que aborda especificamente espaço, não é uma novidade a necessidade de professores para suas aulas.

Então não tinha local, absolutamente nada. Era numa sala, que afastávamos as cadeiras e eu subia em cima da mesa para poder mostrar os exercícios - naquela época nós usávamos o Método Francês - e elas me seguiam. Então era muito restrita a aula. Muito restrita. E era dentro de uma sala. Não fazíamos jogos nem nada disso. Era exclusivamente aquela aula. [...] Jogar bola, exercícios com bola, não tinha condição, não tinha espaço. Então eram só mesmo os exercícios, não é?” (IVETE LUZ BUCK SILVA, 2004, p. 7-8).

Então, foi uma época assim de muita fartura. Nós levávamos sacos de bolas de vôlei, de basquete, de borracha, maça, arco, entendeu? Material de atletismo: peso, disco, dardo. Colchões de ginástica. A escola estava abarrotada. Então você municiava o professor; ele tinha, vamos dizer, material. Ele não poderia, primeiro, reclamar de espaço porque ele tinha quadra, tinha tudo. Material ele tinha de sobra [...].

Nos anos 70, estudos comprovam que houve uma mudança significativa, no decreto 69/450 de 1971 estabelece sessões semanais de educação física o que segundo alguns professores gerou certo conforto na pratica de exercícios, veja o que diz o professor Aluízio Rosa que em 1974/1974 foi Coordenador de educação Física da prefeitura Municipal de Curitiba no Paraná:

Fala-se de forma genérica, ou seja, do ensino regular para alunos com necessidades especiais ou não, referentes às estruturas da escola, entretanto, já na época, a professora Ermínia Piazeetta do mesmo município, relata o seguinte:

Nós tínhamos fartura de material. Espaço era exíguo. Nós não tínhamos nada. Nós íamos para rua, nós íamos na frente das casas que tinham uns vazios, terreno baldio; aproveitávamos tudo. Aqui estava sendo construído e aí começou [...] fizeram uma quadrinha pequenina lá nos fundos e gente usava aquela; dividia entre a gente.

E continua:

Com o tempo fizeram a quadra de cima. Com uma escola deste tamanho o espaço para Educação Física é muito pequeno. Nós não temos espaço aqui. Todo mundo acha que tem, mas para uma escola que tem 40 turmas em um período, a quadra é muito pequena. Eu sempre costumei ir para rua. Peguei quadras lá nos fundos, no Centro Social, no Arion. [...] Porque não havia espaço. Então cada um lutava pelo seu espaço 
Sendo assim, com diversos tipos de questionamentos e discussões antigas, o tema continua sendo relevante, inconcluso e passive de resoluções para a sociedade brasileira.

De acordo com Santos (2003) os professores podem promover a inclusão e a socialização por meio dos benefícios e facilidades que a Educação Física contribui como a proximidade com os alunos e formação de grupos, ao espaço físico amplo que permite maiores vivencias corporais e ao lúdico. Na falta desses espaços, o que não justifica é não promover essa integração. Para além das políticas públicas eficientes, existe um componente que somente o professor tem e esse constitui o diferencial que tem movido a educação pública no Brasil: a boa vontade e o querer fazer.

\section{CONSIDERAÇÕES FINAIS}

A educação física constitui um espaço de encontro, socialização e saber dentro e fora da escola. Nesse sentido precisa e deve ser oportunizada para todos, e muito mais para aqueles que são tolhidos de uma maior participação na sociedade por conta de deficiências que ocasionam necessidades especiais. Segundo Soler (2003) é dever da Educação Física Escolar garantir acesso de todos os alunos às atividades propostas.

Além das garantias legais e constitucionais é uma questão de âmbito humano proporcionar as condições para que essa inclusão ocorra na escola e nas classes regulares. Nesse sentido acredita-se que o aluno não terá que se adequar à escola, mas essa sim deve e precisa se adequar ao aluno, possibilitando formas de inserção e autonomia.

As políticas públicas infelizmente parecem andar na contramão da educação. Onde se avança em direitos internacionais, perde-se em execução, aplicabilidade. Nesse contexto conflituoso, recai sobre o professor e a escola, amparados por um Projeto político pedagógico bem-intencionado, buscar fazer a diferença no sentido de incluir, habilitar, tornar possível e viável o direito dessas crianças com necessidades educacionais especiais.

Nesse ínterim cabe a cada um de nós educadores físicos, buscar melhorar a vida dessas pessoas, em direção a emancipação, autonomia e a tão sonhada inclusão social. 


\section{REFERENCIAS}

ALMEIDA, Marina da S. Rodrigues, Caminhos para uma inclusão humana. Ed. Didática Paulista, São Paulo, fevereiro 2004.

, Marina da S. Rodrigues, Manual para educadores sobre inclusão. Ed. Didática Paulista, São Paulo, fevereiro 2004.

ALVES, D. Educação inclusiva: documento subsidiário à prática de inclusão. Brasília: MEC/SEE, 2005.

AMARAL, Lígia Assumpção. Diferença/deficiência/necessidades educacionais especiais: apontamentos para reflexão/discussão. In: Anais do III Congresso Ibero-Americano de Educação Especial, v. 1, p. 127-128, [Brasília: MEC/Seesp] 1998.

BETTI, M. Educação física escolar: ensino e pesquisa-ação. Ijuí: Unijuí, 2009a. Disponivel em: http://www.educacaofisica.seed.pr.gov.br/. Acesso em: 08 de out. de 2015.

BRASIL. LDB 9.394, de 20 de dezembro de 1996: Lei de Diretrizes e Bases da Educação Nacional. Disponível em: http://portal.mec.gov.br/arquivos/pdf/ldb.pdf. acesso em: 08 de out. de 2015 .

BRASIL. Diretrizes Nacionais para a Educação Especial na Educação Básica. Brasília: MEC/SEESP; 2001. Acesso em: 08 de out. de 2015.

BRASIL. Plano Nacional de Educação - PNE. Brasília: INEP; 2001. Acesso em: 09 de out. de 2015.

BRASIL. Ministério da Educação. Política nacional de educação especial na perspectiva da educação inclusiva. Brasília: MEC/SEESP; 2008. Acesso em: 10 de out. de 2015

BRITO, R. F. A.; LIMA, J. F. Desafios encontrados pelos professores de educação física no trabalho com alunos com deficiência. Corpo, movimento e saúde, Salvador, v.2, n.1, p.1-12, 2012.

CRUZ, G. C. Formação continuada de professores de Educação Física em ambiente escolar inclusivo. Londrina: Eduel, 2008.

JESUS, D. M. O que nos impulsiona a pensar a pesquisa-ação colaborativo-crítica como possibilidade de instituição de práticas educacionais mais inclusivas? In: BAPTISTA, C. R.; CAIADO, K. R. M.; JESUS, D. M. (Org.). Educação Especial: diálogo e pluralidade. Porto Alegre: Editora Mediação, 2008.

KITZINGER, J. Introducing focus groups. $B M J$, v.311, p.299-302, 1995. Disponível em: <http://www.ncbi.nlm.nih.gov/pmc/articles/PMC2550365/pdf/bmj00603-0031.pdf >. Acesso em: 10 de out. de 2015. 
MAZZARINO, J. M.; FALKENBACH, A.; RISSI, S. Acessibilidade e inclusão de uma aluna com deficiência visual na escola e na Educação Física. Rev. Bras. Ciênc. Esporte, Florianópolis.

MANTOAN, M. T.; BATISTA, C. A. Deficiência mental. São Paulo: MEC/SEESP, 2007.

MANTOAN, M.T.E.. Compreendendo a deficiência mental: novos caminhos educacionais. São Paulo: Editora Scipione.1988.

(1991). A solicitação do meio escolar e a construção das estruturas da inteligência no deficiente mental: uma interpretação fundamentada na teoria de conhecimento de Jean Piaget. Tese de doutoramento. Campinas:UNICAMP/Faculdade de Educação.

MAZZARINO, J. M.; FALKENBACH, A.; RISSI, S. Acessibilidade e inclusão de uma aluna com deficiência . Esporte, Florianópolis, v.33, n.1, p.87-102, 2011.

PIAGET, Jean (1976), A Equilibração das Estruturas Cognitivas - problema central do desenvolvimento.(1975) Tradução: Marion M. dos Santos Penna. Rio de Janeiro: Zahar Editores.

RONDINELLI, Paula in A educação física como disciplina escolar. Disponível em http://www.brasilescola.com/educacaofisica/ acesso dia 28 de agosto de 2016.

SOUZA, Luciane Porto Frazão de. Representações Sociais: Um Olhar Sobre os Processos de Inclusão Educacional. A Dimensão das Tecnologias Assistivas em Ambientes Inclusivos. Tese de Doutorado. Unilogos. Rio de Janeiro. 2016.

STAINBACK, Susan, Inclusão: um guia para educadores/ Susan Stainback e Willian Stainback; trad. Magda França Lopes - Porto Alegre: Artes Médicas Sul, 1999. 